\title{
Water and agriculture: a love/hate relationship
}

\section{Graham McAuliffe}

Department of Geography, School of the Human Environment, and School of Biological, Earth and Environmental Sciences, UCC

Water is life's mater and matrix, mother and medium. There is no life without water

(Albert Szent-Gyorgyi).

\section{Setting the scene}

\section{Water}

Although the majority of our planet is covered with water, 97 per cent of this is unsuitable for human consumption as it is too salty. Most of the remaining 3 per cent is found in landice which is predominately inaccessible, leaving less than 1 per cent available to humans and other animals in surface and ground waters. Water transports many substances, such as nutrients required by organisms, e.g. nitrogen $(\mathrm{N})$ and phosphorus $(\mathrm{P})$, but also many pathogens that cause disease. As a result, ensuring an adequate quantity of good quality water is critical to ensure human and ecosystem health into the future.

\section{Agriculture}

Food is equally important to human survival. Many other essential ingredients for life, such as carbohydrates, proteins, and fats, are only found in certain foods. This means agriculture is the most important activity on Earth, and accounts for about 80 per cent of freshwater usage; thus, the two resources are inextricably linked.

Traditionally, agriculture would not have been quite as demanding on water use. Across Europe before the introduction of the Common Agricultural Policy, farming was carried out on mixed farms which combined the growing of crops and raising of animals. From the nineteen sixties, however, European policy began encouraging farmers to maximise production outputs by specialising in a single crop or livestock system. A drive for adopting mechanisation and intensive production has since changed farming in Europe considerably. For example, the majority of pig production now occurs in indoor units which house thousands of animals at once. Not only does this increase water demands, it also increases pressures on the environment by generating higher levels of manure which, if managed 
inefficiently, can lead to excess nutrients entering water-bodies causing ecological deterioration.

\section{A love/hate relationship}

While agriculture relies heavily on the availability of water for the production of crops and livestock, the relationship is in some senses one-sided. As mentioned previously, water is an essential source of nitrogen and phosphorus for organisms. Take nitrogen, for example, the most abundant element in the atmosphere but which is useless to us in its gaseous form, $\mathrm{N}_{2} . \mathrm{N}_{2}$ must be broken down, or fixed, to ammonia $\left(\mathrm{NH}_{3}\right)$ by bacteria before it is accessible to plants and animals. Phosphorus, on the other hand, is not found as a gas in the atmosphere. Instead, it is stored in rocks as phosphates and usually enters water naturally after erosion has occurred. Though essential for the growth of life, excessive quantities of nitrogen and phosphorus in waterways can result in the water becoming unsuitable for many common uses. This is where a major crack in the relationship forms.

When we eat plants or animals containing nitrogen and phosphorus, our bodies take up a certain amount of the nutrients. The surplus nutrients are then excreted. The same can be said for livestock. When thousands of animals are housed in relatively small areas, however, their excreta can become problematic. Pigs' manure, for instance, is usually high in phosphorus which makes it a good natural fertiliser for tillage farmers. Nevertheless, if excessive amounts of phosphorus are spread on land, it runs the risk of runoff or erosion into rivers and streams. Nitrogen in the form of nitrate is also beneficial to crops. However, nitrate is very soluble, meaning that it not only reaches surface waters with run-off but can percolate through the soil to the groundwater below. Nitrogen as ammonium $\left(\mathrm{NH}_{4}{ }^{+}\right)$is also found in manure. From ammonium, ammonia $\left(\mathrm{NH}_{3}\right)$ is often lost to the atmosphere through volatilisation, a process whereby the compound vaporises to its gaseous state. It can, however, form an aqueous solution if it comes in contact with water prior to volatilisation occurring. In this liquid state, ammonia can find its way to waterways through runoff.

\section{Too much of a good thing}

Nitrogen and phosphorus are often considered limiting factors in the growth of populations of some species in ecosystems. This means that without enough of these nutrients, certain organisms will not be able to grow. On the other hand, excessive amounts of nitrogen and phosphorus in aquatic systems lead to a process known as eutrophication. Eutrophication promotes the growth of simple plant organisms such as macroalgae, or seaweeds, and phytoplankton. Phytoplankton, the most common of which is algae, tends to inhabit the upper levels of the water column and flourish with increased nutrient levels. Consequently, these algal blooms prevent sunlight from reaching plants in the lower 


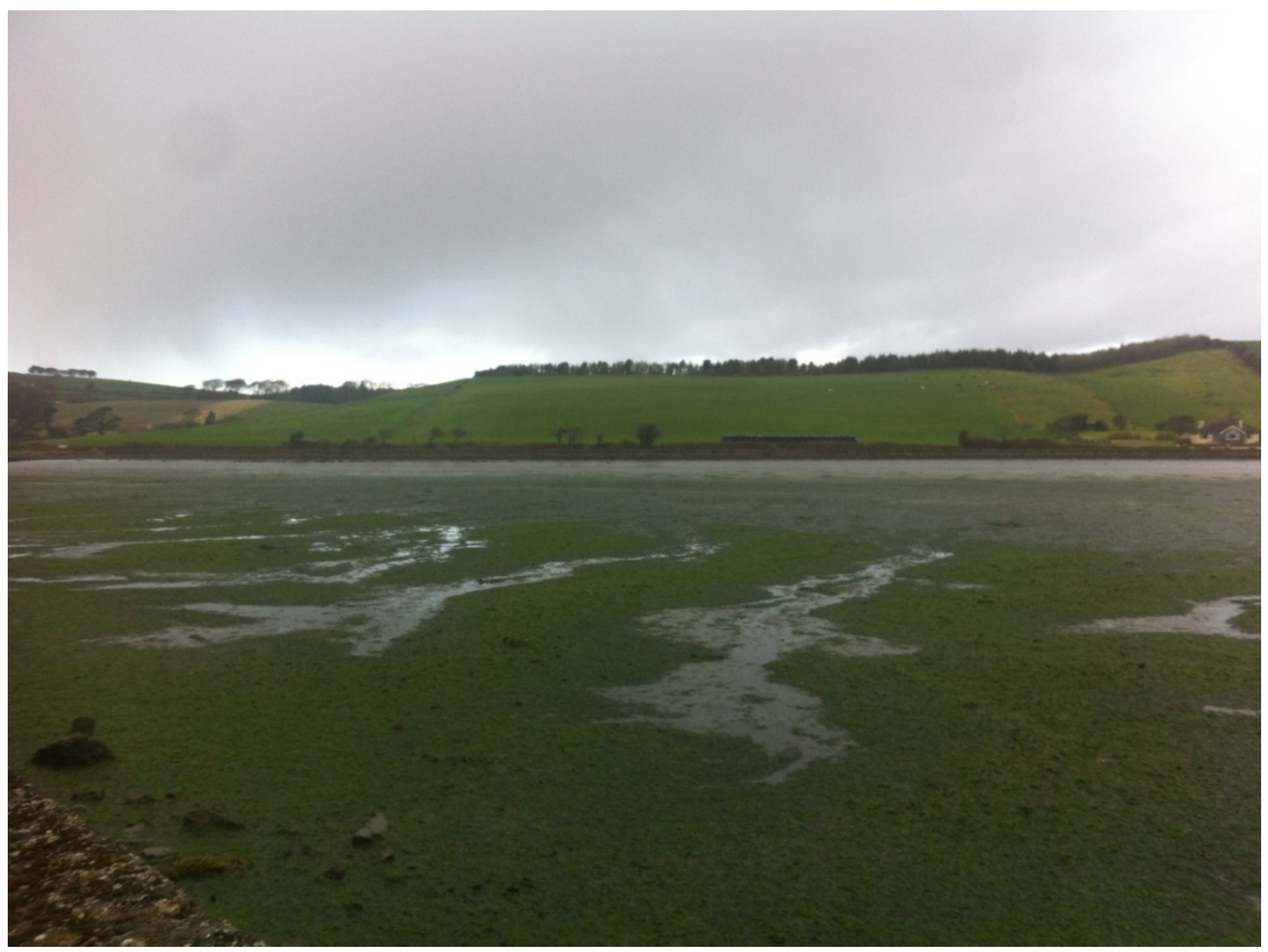

Figure 1: - Sea lettuce bloom in Courtmacsherry Bay recorded in October 2012. Source: Graham McAuliffe.

levels; thus, inhibiting their photosynthesis. Once the algae have consumed the nutrients in the water, they die off and fall to the bottom of the water-body as bacteria begin decomposing the organisms. The bacteria that break down the algae consume oxygen, and because photosynthesis is prevented, oxygen production by plant-life is halted. Without oxygen, higher trophic organisms such as salmon cannot survive and either die off or migrate. This not only has an impact on the biodiversity of a river, it also reduces the value of the water because fishing tourists may stop visiting an area.

Transitional waters, such as estuaries, can also be affected. Figure 1 demonstrates the severity of a sea lettuce (Ulva maxima) bloom as a consequence of nutrient enrichment in Courtmacsherry Bay, Co. Cork. Rather than a depletion of oxygen, however, here the seaweed is becoming stranded on the shore and decomposing thereafter. Though the primary source of nutrients in the estuary is disputed, the effects are not. The algal bloom has had a devastating impact on locals and tourists alike. Many boats' engines, for instance, have been destroyed by the infestation, and the area can be plagued by noxious odours, especially on hot days. In 2009 a taskforce was set up, funded by taxpayers, to remove the dead vegetation from the area. However, the team was unable to remove adequate amounts resulting in the area still being plagued by this manmade nuisance today. 


\begin{tabular}{|c|c|c|c|}
\hline WFD Ecological Status & Trophic Status & Water Quality & Q-Values \\
\hline High & Ultra-oligotrophic & Unpolluted & $5,4-5$ \\
\hline Good & Oligotrophic & Unpolluted & 4 \\
\hline Moderate & Mesotrophic & Slightly Polluted & $3-4$ \\
\hline Poor & Eutrophic & Moderately Polluted & $3,2-3$ \\
\hline Bad & Hypertrophic & Seriously Polluted & $2,1-2,1$ \\
\hline
\end{tabular}

Figure 2: - Breakdown of river water quality determined by the Water Framework Directive. Source: EPA.

Ammonia can also be a concern for aquatic ecosystems. Under certain conditions, determined by $\mathrm{pH}$ and temperature, ammonia can be highly toxic to fish resulting in disfigurations or death.

\section{Rekindling the flame}

Water and agriculture's faltering relationship has not gone unnoticed. In an attempt to protect European waterways, the EU developed the Water Framework Directive (WFD) in 2000. The aim of the directive is to ensure all aquatic resources in the EU reach good or high ecological status. For rivers and streams in Ireland, this means achieving a Q-Value of 4 or greater. Q-Value standards are determined by the biological diversity observed in rivers. The associated categories are represented in Figure 2. Based on Q-Values, water sources are divided into the following four categories based on their potential to reach specified goals: at risk; probably at risk; probably not at risk; not at risk. The 'probably' categories acknowledge that sufficient data are unavailable, but when they are acquired, the outcomes are probable based on current records.

\section{The research project}

Ongoing freshwater monitoring by the Environmental Protection Agency (EPA) highlights the fact that agriculture is the greatest contributor to slight and moderate pollution in Ireland. The EPA's findings, however, do not delineate the amount of pollution derived from individual sectors. Therefore, the novelty of this project manifests in determining the contribution of the pig sector to river water quality. The pig industry in Ireland is highly regulated by the EPA and local authorities; but, to the best of this author's knowledge, research to date has not considered risks posed to water bodies when intensive pig farms are concentrated in one particular area. 


\section{Methodology}

Based on information available from the EPA, a river and its tributary have been identified as a study site. To protect the identity of participants in the study, the location of the study site cannot be revealed. Nevertheless, the EPA has acknowledged that the rivers are at risk and probably at risk, respectively, of not reaching WFD goals. Despite an urban wastewater treatment plant (UWWTP) being highlighted as the primary polluter in the area, consultants tasked with assessing the river basin district note that piggeries in close proximity to the rivers may also be contributing to some of the pollution detected.

In order to accurately assess the contribution of the piggeries, an environmental risk assessment (ERA) methodology is being used. This methodology is usually a desk-based approach reliant on secondary data; however, as a result of insufficient information and data, this project is modifying a typical ERA by acquiring primary data. The first step in an ERA is to identify hazards, such as nitrates, ammonia, phosphates and pathogens, for instance. The ERA then determines the risks they pose to human and ecological health by assessing the Predicted Environmental Concentrations (PECs) against the Predicted No-Effect Concentrations (PNECs), taking exposure pathways into account.

This ERA is a multidisciplinary study which draws upon a range of tools. For example, all available secondary data is currently being examined to determine potential hazards. Interviews with the rivers' recreational users and local residents will be conducted to establish perceived risks and potential exposure routes. Water sampling and chemical and biological analyses will be carried out to fill gaps in available data. A sampling site can be seen in Figure 3. Once sufficient data have been acquired, statistical and hydrological models will be created to predict future risk to water quality in the area.

\section{Preliminary findings}

According to The Central and Regional Fisheries Board, one of the rivers is inhabited by brown trout (Salmo trutta) and salmon (Salmo salar), making it an important recreational river. The report notes that trout tend to grow slowly in the water-body. An Annual Environmental Report (AER) of the UWWTP effluent shows that the plant has been discharging an average of $2.633 \mathrm{mg}$ ammonia $\mathrm{L}^{-1}$ per annum. In addition to the chronic loss of ammonia from the UWWTP, AERs from certain piggeries suggest that acute losses of ammonia also occur sporadically. The United States EPA advises that chronic $\mathrm{NH}_{3}$ levels at $1.9 \mathrm{mg} \mathrm{L}^{-1}$ or acute levels at $17 \mathrm{mg} \mathrm{L}^{-1}$ can be toxic to fish. These findings indicate that $\mathrm{NH}_{3}$ is a hazard in the study region which might account for the slow brown trout growth rates observed by The Central and Regional Fisheries Board. Other hazards are currently being identified. 


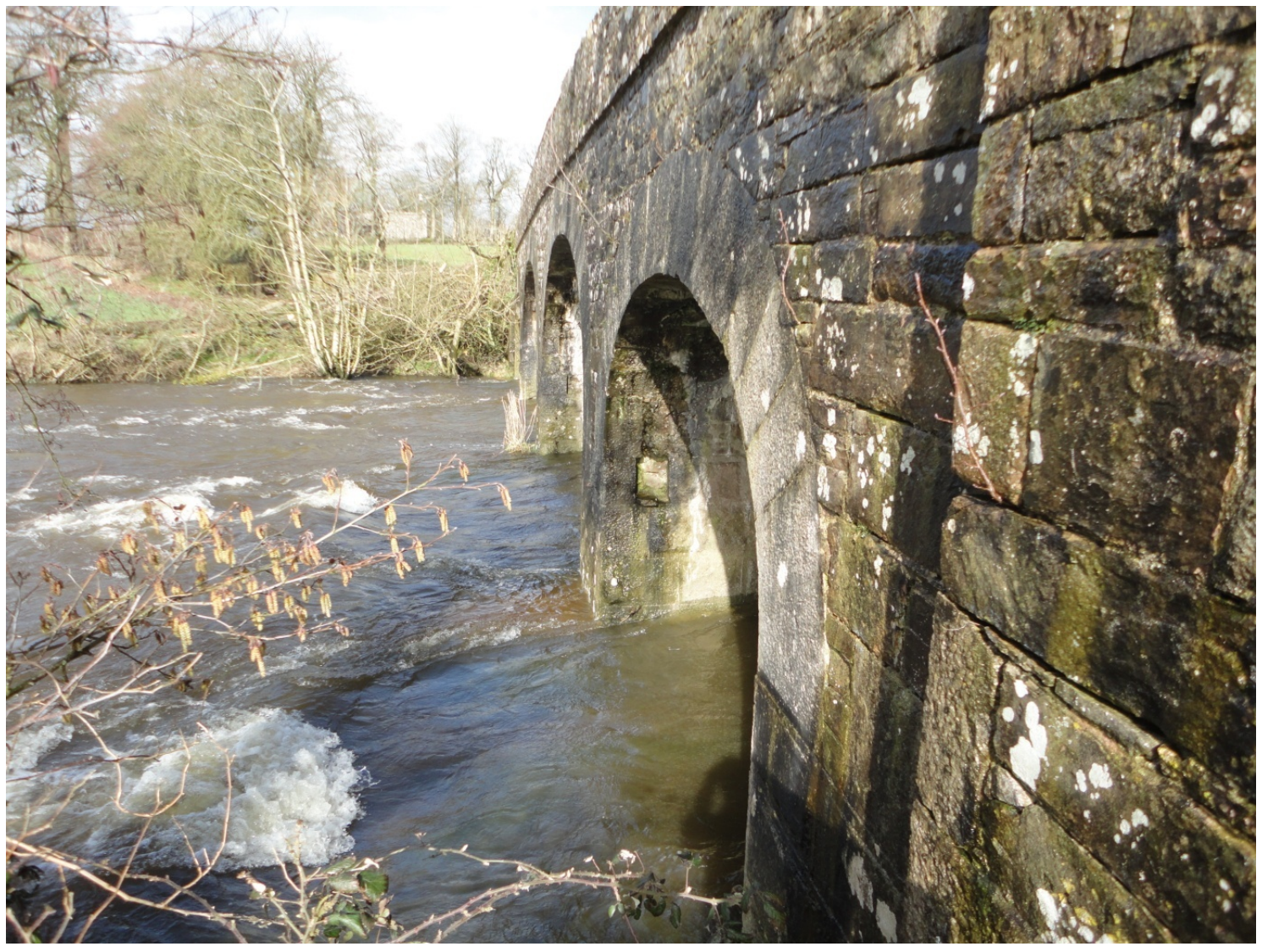

Figure 3: - A photograph displaying a sampling site at a bridge located in the study region. Steps provide access to the river from the bridge above. Source: Graham McAuliffe.

\section{Expected outcomes}

This research will complement work carried out by the EPA and Teagasc under the WFD. While extensive water monitoring has been carried out nationwide, gaps in knowledge exist. By examining the contribution of the pig sector to water pollution in a small area, and predicting risks of future possibilities, this project will advance knowledge of Ireland's freshwater quality and its potential of achieving WFD goals. A model for risk assessment of agricultural inputs to water systems is being developed using a range of methods across numerous disciplines. Future research will be able to utilise this approach to determine the risks individual agricultural activities pose to surface water quality both nationally and internationally.

I would like to acknowledge the Department of Geography, UCC, for funding this project. I would also like to thank my supervisors, Drs Colin Sage and Deborah Chapman, for their regular feedback and advice. 